\title{
pH-responsive PMAA- $b$-PEG-b-PMAA triblock copolymer micelles for prednisone drug release and release kinetics
}

\author{
Yan-Ling Luo $\cdot$ Wei Yu $\cdot$ Feng Xu
}

Received: 17 March 2012/Revised: 10 May 2012/ Accepted: 21 May 2012/

Published online: 4 June 2012

(C) The Author(s) 2012. This article is published with open access at Springerlink.com

\begin{abstract}
H}$-sensitive hydrophilic poly(methacrylic acid)- $b$-poly(ethylene glycol)- $b$-poly(methacrylic acid) (PMAA- $b$-PEG- $b$-PMAA) triblock copolymers were synthesized through atom transfer radical polymerization, and were characterized by FT-IR, ${ }^{1} \mathrm{H}$ NMR, and GPC. The as-synthesized polymers can self-assemble into stable and almost spherical nanomicelles in aqueous solution with an average size range from 18 to $89 \mathrm{~nm}$, depending on the micellar concentrations, while they assumed well-defined spherical morphologies in PBS solutions. The micellization behavior in different media was investigated by a fluorescence spectroscopy technique, UV-Vis transmittance, and dynamic light scattering measurements. The critical micelle concentration and size of the micelles decrease with the increasing the length or molecular weights of PEG and PMAA chains. A pH-dependent phase transition behavior produces at a $\mathrm{pH}$ value of about 5.2, and the stable $\mathrm{pH}$ micellization behavior varied within a narrow $\mathrm{pH}$ range from ca. 4.8 to 7.4. These triblock copolymers are generally low cytotoxicity at a micellar concentration below $400 \mathrm{mg} \mathrm{L}^{-1}$, as revealed by the MTT assay. The prednisone release and release kinetics studies disclosed that these $\mathrm{pH}$-sensitive polymeric micelles are good carriers for the drug delivery.
\end{abstract}

Keywords Copolymers $\cdot \mathrm{pH}$-sensitivity $\cdot$ Micelles $\cdot$ Cytotoxicity · Drug release kinetics

\footnotetext{
Y.-L. Luo $(\bowtie) \cdot$ W. Yu · F. Xu $(\bowtie)$

Key Laboratory of Macromolecular Science of Shaanxi Province, School of Chemistry \& Chemical Engineering, Shaanxi Normal University, Xi'an 710062, People's Republic of China

e-mail: luoyanl@snnu.edu.cn

F. $\mathrm{Xu}$

e-mail: fengxu@snnu.edu.cn
} 


\section{Introduction}

In the past decades, stimuli-responsive materials have attracted rapidly growing interest because of their potential biomedical and pharmaceutical applications [1-3]. Specifically, poly( $N$-isopropylacrylamide) (PNIPAAm) and poly(methylacrylic acid) (PMAA) have been focused on thermo- and $\mathrm{pH}$-sensitive behavior [4-6]. Since $\mathrm{pH}$ sensitive carriers can target drugs to deep organs or tumor tissues, PMAA-based amphiphilic block copolymer micelles have widely been investigated for these applications. It is reported that the extracellular $\mathrm{pH}$ range in most solid tumor tissues is from 5.7 to 7.8 [7]. Therefore, it is a challenging subject to exploit a system capable of responding to such a narrow window of $\mathrm{pH}$ change. Recently, the core-shell nanoparticles from poly(L-histidine)-block-poly(ethylene glycol) were reported to dissociate at $\mathrm{pH} 7.0$ to 7.4 , thereby releasing the enclosed doxorubicin [8,9]. Poly(ethylene glycol) (PEG) is one of the most commonly used hydrophilic polymers, which possesses highly biocompatible, and can be rapidly and spontaneously cleared from human bodies as excellent candidates of biomedical materials [10]. Therefore, PEG-containing copolymer micelles have also been appreciated. These polymeric micelles as colloidal nanoparticles have been researched as the nano-containers carrying drugs [11-14].

The architecture of polymers determines the static and dynamic stability, morphology, size, and size distribution of the micelles, and further affects the performance of micelles including drug loading and release rate, even in vivo circulation and distribution [13]. Generally, when the corona block is longer than the core block, the shape of the resulting micelles is spherical. Conversely, increasing the length of the core segment beyond that of the corona-forming chains may generate various non-spherical structures, including rods and lamellae [15]. To achieve the copolymers having controllable structure and morphologies, atom transfer radical polymerization (ATRP) is a better bet, which can yield well-defined high molecular weight and narrow molecular weight distributions. Compared to other "living" radical systems, ATRP represents a simple, inexpensive, and more general method for controlled radical polymerization [16]. It has been previously employed to prepare polymers of varying morphologies, including block copolymers and star polymers by ATRP [17-19].

Prednisone is in a class of drugs called corticosteroids, which can prevent the release of substances in the body that cause inflammation. It is usually used to treat many different conditions such as allergic disorders, skin conditions, ulcerative colitis, arthritis, lupus, psoriasis, or breathing disorders. Stimuli-responsive amphiphilic block copolymers as biomaterials may self-assemble and form micelles in organic or aqueous media and can be used to load the hydrophobic drug. Ideally, these nanoparticles should circulate until they reach the target organs or tissues, either by specific targeting [20]. The $\mathrm{pH}$ variations in some therapeutic targets such as tumors, and inflammation or ischemia sites are slight and the chemical trigger should respond efficiently to these variations, while being stable at neutral $\mathrm{pH}$ [21]. Sun et al. [22] reported synthesis and micellization of double-hydrophilic pH-responsive poly(acrylic acid)- $b$-poly(ethylene oxide)- $b$-poly (acrylic acid) (PAA- $b$-PEO- $b$-PAA) triblock copolymers. Tao and Liu [23, 24] synthesized 
poly(methylacrylic acid)-poly(ethylene glycol)-poly(methylacrylic acid) (PMAA$b$-PEG- $b$-PMAA) triblock copolymers, and investigated their $\mathrm{pH}$-sensitivity.

Based on the above description, we focused on a $\mathrm{pH}$-response triblock copolymer system that may potentially serve as a molecular platform for drug delivery applications. The triblock copolymers consist of PEG blocks with non-toxicity and PMAA blocks with $\mathrm{pH}$-sensitivity, named PMAA- $b$-PEG- $b$-PMAA, and were synthesized via esterification, ATRP and hydrolysis successively. The supramolecular self-assembly behavior of the as-prepared copolymers in different media was examined by a fluorescent probe technique, UV-Vis transmittance, dynamic laser scattering (DLS), and transmission electron microscopy (TEM). Compared with the work by Sun et al. [22], the PMAA- $b$-PEG- $b$-PMAA triblock copolymer micelles assembled in our current study are anticipated to be more stable than the PAA- $b$ PEO- $b$-PAA ones due to hydrophobic stabilization of the hydrogen bonds by the $\alpha$-methyl groups. Meanwhile, the interpolymer complexes containing PMAA and PEG may occur over a wider $\mathrm{pH}$ range than those containing PAA and PEG [25], which is believed to be in favor of the formation of stable micelles. In comparison with the work by Tao and Liu [23, 24], a remarkable merit of the current drug release system is the study of drug release kinetics and transport mechanism, especially in the simulated physiological medium of $\mathrm{pH} 7.4$ and $37^{\circ} \mathrm{C}$, which is much meaningful in obtaining physically meaningful parameters for comparative purposes and relating some release parameters such as bioavailability. Consequently, an effective target therapy against lesion tissues for these polymeric micelles may be accomplished by a combination of selective delivery to lesion sites based on stable micellar structures and $\mathrm{pH}$-induced response. Meanwhile, the physiochemical properties with different component ratios or block lengths and the cytotoxicity of the triblock copolymer micelles in various media were extensively examined to acquire information about the potential for biomedical applications. We expect that the $\mathrm{pH}$-responsive copolymer micelles can be employed as a promising nano-leveled carrier for intravenous injection and oral drug delivery.

\section{Experimental section}

Materials and reagents

The monomer, $t$-butyl methacrylate ( $t$ BMA, $99 \%$ ), was supplied by the Aladdin Corp., USA, and used as received. Copper(I) bromide $(\mathrm{CuBr})$ was stirred in glacial acetic acid for $48 \mathrm{~h}$, filtered and washed with absolute ethanol, diethyl ether and then dried under vacuum. 2-Bromoisobutryl bromide (99\%), 1,1,4,7,7-pentamethyldiethylenetriamine (PMDETA, $98 \%$ ), and prednisone (98\%), all from Aladdin Chem. Co. Ltd, were used without further purification. PEG, biological grade, with molecular weight $\left(M_{\mathrm{W}}\right)$ of 2,000 and 5,000, was supplied by the SigmaAldrich, and used as received. Chloroform $\left(\mathrm{CHCl}_{3}\right)$ was dried by refluxing and distilling over calcium hydride. Analytical triethylamine (TEA) was purchased from the Tianjin Fuchen Chem. Reagent Factory (China), and was refluxed with $p$-toluenesulfonyl chloride, distilled and stored over $\mathrm{CaH}_{2}$. Isopropanol $(i-\mathrm{PrOH})$ 

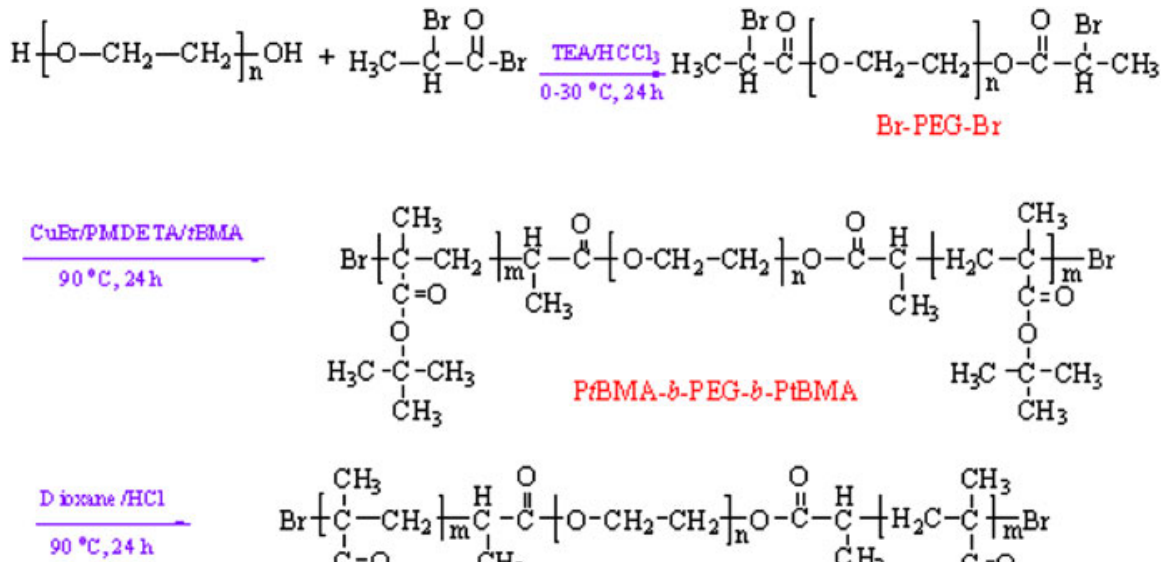<smiles>CCCCC(C)(Br)C(=O)O</smiles><smiles>CCCCCCC(C)CC(C)C(=O)OCCOC(C)(C)C</smiles>

Scheme 1 Synthetic scheme of representative PMAA- $b$-PEG- $b$-PMAA triblock copolymer

and 2-butanone, supplied by the Sinopharm Chemical Reagent Co., Ltd, were used as received. All other reagents such as tetrahydrofuran (THF) and dioxane, etc., are available from commercial markets.

Synthesizing procedures

The amphiphilic P $t$ BMA- $b$-PEG- $b$-P $t$ BMA triblock copolymer and $\mathrm{pH}$-sensitive PMAA- $b$-PEG- $b$-PMAA triblock polymer were synthesized according to the following three steps, as shown in Scheme 1: (1) preparation of macromolecular initiator, Br-PEG-Br; (2) synthesis of amphiphilic P $t$ BMA- $b$-PEG- $b$-P $t$ BMA triblock copolymer; and (3) hydrolysis of amphiphilic PtBMA- $b$-PEG- $b$-P $t$ BMA triblock copolymer to achieve $\mathrm{pH}$-sensitive PMAA- $b$-PEG- $b$-PMAA triblock polymer.

\section{Synthesis of PEG macroinitiators}

For a typical experiment, in a three-neck round-bottom flask, 2 mmol PEG and $8 \mathrm{mmol}$ TEA were dissolved in $40 \mathrm{~mL}$ dried $\mathrm{CHCl}_{3}$ in a flask. After the solution was cooled in an ice-water bath to $0{ }^{\circ} \mathrm{C}, 8 \mathrm{mmol}$ 2-bromopropiomyl bromide dissolved in $10 \mathrm{~mL}$ dried $\mathrm{CHCl}_{3}$ in advance was added dropwise in $1 \mathrm{~h}$ under dried $\mathrm{N}_{2}$. The reaction was kept at $0{ }^{\circ} \mathrm{C}$ for $3 \mathrm{~h}$, and then at room temperature for $24 \mathrm{~h}$ with stirring. After the reaction was completed, the solution was concentrated by rotary evaporation to remove most of the solvent prior to precipitation into tenfold THF and filtration to remove the white solid product. The filtrate was concentrated by rotary evaporation, and then precipitated in tenfold cold diethyl ether. The $\mathrm{Br}-\mathrm{PEG}-\mathrm{Br}$ macroinitiators were collected by filtration and dried at room temperature under vacuum for $24 \mathrm{~h}$ (mean yield: $80 \%$ ). The end-group functionality was determined by proton nuclear magnetic resonance ( ${ }^{1} \mathrm{H}$ NMR) spectroscopy. 
The synthesis of amphiphilic P $t$ BMA- $b$-PEG- $b$-P $t$ BMA triblock copolymer was accomplished by ATRP (Scheme 1). Typically, $0.1 \mathrm{mmol} \mathrm{Br}-\mathrm{PEG}-\mathrm{Br}$ macroinitiator, 150 mmol tBMA, $0.1 \mathrm{mmol}$ PMDETA, and magnetic bar were charged into a predried Schlenk flask. $\mathrm{CuBr}(0.1 \mathrm{mmol})$ was rapidly introduced into the flask to allow formation of the $\mathrm{CuBr} / \mathrm{PMDETA}$ complex. The solvent which is composed of $10 \mathrm{~mL}$ 2-butanone/ $i$-PrOH (7:3 v/v) added at last. A three 'freeze-pump-thaw' cycle was performed to exclude oxygen from the polymerization solution. The reaction flask was sealed and placed in a $90{ }^{\circ} \mathrm{C}$ oil bath. After $24 \mathrm{~h}$, the Schlenk flask was opened and the reaction mixture was diluted with THF. The thinned mixture was passed through an alumina column to purify the polymer. Finally, the polymer was recovered by precipitating it into tenfold excess methanol/water $(1 / 1 \mathrm{v} / \mathrm{v})$ mixture, filtered, and dried under vacuum to a constant weight (mean yield: $47 \%)$.

\section{Synthesis of PMAA-b-PEG-b-PMAA triblock copolymers by hydrolysis}

The required amount of P $t$ BMA- $b$-PEG- $b$-P $t$ BMA triblock copolymer and magnetic bar were added into the round-bottom flask with a certain amount of dioxane and $\mathrm{HCl}(36.5 \%)$. The mixture was then stirred at $90{ }^{\circ} \mathrm{C}$ for $24 \mathrm{~h}$. After the reaction was completed, the mixture was precipitated in cold diethyl ether, filtered, and the products were then dried under vacuum to a constant weight (mean yield: $36 \%$ ).

\section{Micelle formation}

The PMAA- $b$-PEG- $b$-PMAA triblock copolymer micelle suspension in aqueous media was prepared via a membrane-dialysis method. Briefly, the copolymer $(50 \mathrm{mg})$ was dissolved in $10 \mathrm{~mL}$ DMF to obtain an initial concentration of $5,000 \mathrm{mg} \mathrm{L}^{-1}$. Then the solution was put into a dialysis tube (molecular weight cutoff: $5,000 \mathrm{~g} \mathrm{~mol}^{-1}$ ) and subjected to dialysis against 1,000 mL de-ionized water for $48 \mathrm{~h}$ with vigorous stirring. The water was replaced over night, especially changed once per hour in first $3 \mathrm{~h}$. The solution changed from transparent to translucent during the dialysis, which is thought to be the evidence of micelle formation. The concentration of the micellar solution was quantified as $1,000 \mathrm{mg} \mathrm{L}^{-1}$, and then diluted with deionized water or PBS solutions to the desired concentration for further measurements.

Characterization and measurements

\section{FT-IR and ${ }^{1} \mathrm{H}$ NMR measurements}

Fourier transform infrared (FT-IR) spectra were recorded on an AVATAR 360 ESP FT-IR spectrometer (Nicolet, USA). Samples were pressed into potassium bromide (KBr) pellets. ${ }^{1} \mathrm{H}$ nuclear magnetic resonance $\left({ }^{1} \mathrm{H}\right.$ NMR) spectra of the amphiphilic PtBMA- $b$-PEG- $b$-P $t$ BMA and $\mathrm{pH}$-sensitive PMAA- $b$-PEG- $b$-PMAA triblock 
copolymers were recorded on a Varian Unity $300 \mathrm{MHz}$ NMR spectrometer (Bruker Avance, Germany) with $\mathrm{CDCl}_{3}$ and $d_{6}$-DMSO as solvents, respectively, and TMS was used as internal standard.

\section{GPC measurements}

Number- and weight-average molecular weights $\left(M_{\mathrm{n}}\right.$ and $M_{\mathrm{w}}$, respectively) as well as polydispersity index of the as-synthesized triblock copolymer were determined by a Waters-Breeze gel permeation chromatograph (GPC, Waters, USA) equipped with a Waters 717 plus autosample, a Waters 1515 isocratic HPLC pump, a Waters 2695D separation module and Waters 2414 refractive index detector. The dried copolymers were dissolved in THF (for PtBMA- $b$-PEG- $b$-P $t$ BMA) and DMF (for PMAA- $b$-PEG- $b$-PMAA) and filtered through a $0.45-\mu$ meedle-type ultrafiltration membrane (organic, Ф13) prior to the measurement. Chromatographic THF and DMF were used as the eluent at a flow rate of $1.0 \mathrm{~mL} \mathrm{~min}{ }^{-1}$ at $35{ }^{\circ} \mathrm{C}$. Waters millennium module software was used to calculate molecular weight on the basis of a universal calibration curve generated by a polystyrene standard of narrow molecular weight distribution.

\section{Determination of micellization behavior}

The $\mathrm{pH}$-sensitivity and critical micelle concentration (CMC) of the block copolymers in aqueous and phosphate buffered saline (PBS) solutions were estimated by fluorescence probe method using pyrene as a fluorescence probe. A predetermined amount of pyrene solution in acetone was added into a series of volumetric flasks, and subsequently the acetone was completely removed by evaporation for $2 \mathrm{~h}$. The final concentration of pyrene in the copolymer solution (deionized water or PBS solutions) in each flask was adjusted to $6.0 \times 10^{-7} \mathrm{~mol}$ $\mathrm{L}^{-1}$, while the concentrations of the triblock copolymers were varied from $1.0 \times 10^{-2}$ to $1,000 \mathrm{mg} \mathrm{L}^{-1}$. The combined solution of pyrene and copolymer was equilibrated at room temperature in a dark room for $24 \mathrm{~h}$ before measurements. Fluorescence excitation spectra were recorded at room temperature on a PE LS55 fluorescence spectrophotometer (PE, USA) from 310 to $350 \mathrm{~nm}$ with an emission wavelength of $394 \mathrm{~nm}$. The CMC and $\mathrm{pH}$-sensitivity were taken from the intensity ratios of $I_{338}$ to $I_{334}$ as a function of logarithm of polymer concentration and $\mathrm{pH}$, respectively.

In addition, the UV-Vis transmittance at wavelength of $500 \mathrm{~nm}$ was also used to monitor the turbidity associated with the phase behavior at different $\mathrm{pH}$ values (the micellar solution has concentration of $100 \mathrm{mg} \mathrm{L}^{-1}$ ) with a U-3900/3900H UV-Vis spectrophotometer (Hitachi, Japan). The apparatus was calibrated using PBS solutions with different $\mathrm{pH}$ values.

\section{TEM observations}

The morphology and size of the PMAA- $b$-PEG- $b$-PMAA triblock copolymers were observed using a JEOL JEM-1210 transmission electron microscope (TEM, 
Electron Corp., Japan) at an acceleration voltage of $200 \mathrm{kV}$. Before measurements, a drop of micelle suspension (the concentration is 100 and $500 \mathrm{mg} \mathrm{L}^{-1}$ corresponding to the PBS and aqueous solutions, respectively) was placed on a copper grid with a Formvar film and dried at room temperature and $37{ }^{\circ} \mathrm{C}$ (physiological temperature), followed by negative staining of phosphotungstic acid (2.0\%, pH 4-5).

\section{Dynamic laser light scattering measurements}

The hydrodynamic size and size distribution (polydispersity) of the as-prepared copolymer micelles were evaluated by dynamic laser light scattering (DLS, BI-90Plus, USA) equipped with an ALV-5000 multi- $\tau$ digital time correlator and an argon ion laser operating at $\lambda=660 \mathrm{~nm}$ and output power of $15 \mathrm{~mW}$. The micelle aqueous solution (100 and $500 \mathrm{mg} \mathrm{L}^{-1}$ ) was passed through a $0.45 \mu \mathrm{m}$ pore size filter directly into the scattering cell before measurements. Scattered light was collected at a fixed angle of $90^{\circ}$ for duration of $10 \mathrm{~min}$. The DLS measurements were performed at $25^{\circ} \mathrm{C}$ and a simulated physiological temperature, and all data were averaged over three measurements unless noted otherwise.

In vitro cytotoxicity tests

Cytotoxicity of the copolymer micelles was measured against L929 mouse embryonic fibroblasts by MTT assay. The cells were seeded in a 96-well plate at the density of $1 \times 10^{4}$ cells well ${ }^{-1}$ and incubated in a complete Dulbecco's modified eagle's medium containing $10 \%$ hyclone fetal bovine serum (high glucose DMEM) at $37{ }^{\circ} \mathrm{C}$ in $5 \% \mathrm{CO}_{2}$ for $24 \mathrm{~h}$ before assay. Then, the culture medium was removed and replaced with $100 \mu \mathrm{L}$ of the medium containing triblock copolymer micelles with particular concentrations. After culture for $72 \mathrm{~h}$, the medium was replaced by $100 \mu \mathrm{L}$ of fresh DMEM, followed by adding $25 \mu \mathrm{L}$ of MTT stock solution $\left(5 \mathrm{mg} \mathrm{mL}^{-1}\right.$ in PBS) to the fibroblasts. After incubation for an additional $4 \mathrm{~h}$, the supernatant was discarded, and then $150 \mu \mathrm{L}$ of DMSO was added and shaken for $10 \mathrm{~min}$ at room temperature. For reference purposes, cells were seeded in a fresh culture medium (negative control) under the same conditions. Each assay was performed four times. The optical density (OD) was monitored at $490 \mathrm{~nm}$ by a 96-well universal microplate reader (Model 680, Bio-Rad laboratories (UK) Ltd), and the relative cell viability was calculated using the following equation:

$$
\text { Cell relative viability } \%=\left(\mathrm{OD}_{\text {samples }} / \mathrm{OD}_{\text {control }}\right) \times 100 \%
$$

where $\mathrm{OD}_{\text {control }}$ was obtained in the absence of copolymer and $\mathrm{OD}_{\text {sample }}$ was obtained in the presence of copolymers. In this assay, the Student's $t$ test was used to determine the significance of any pairs of observed differences. Differences were considered statistically significant $p<0.05$. All quantitative results are reported as mean values \pm standard deviation. 
Loading and in vitro releasing of prednisone

$20 \mathrm{mg} \mathrm{PMAA}_{25}-b-\mathrm{PEG}_{90}-b-\mathrm{PMAA}_{25}$ and $20 \mathrm{mg}$ prednisone were dissolved in $2 \mathrm{~mL}$ of DMF. The solution was put into a dialysis tube (molecular weight cut-off: $5,000 \mathrm{~g} \mathrm{~mol}^{-1}$ ) and subjected to dialysis against $1,000 \mathrm{~mL}$ of distilled water for $6 \mathrm{~h}$. After dialysis, the dialysis tube was directly immersed into $400 \mathrm{~mL}$ of distilled water or PBS solution. Aliquots of $3 \mathrm{~mL}$ were withdrawn from the solution periodically. The volume of solution was held constant by adding $3 \mathrm{~mL}$ of distilled water or PBS solution after each sampling. The amount of prednisone released from the micelles was measured using UV absorbance at $240 \mathrm{~nm}$. The concentration of prednisone in distilled water $(C)$ was obtained based on the standard curve:

$$
C\left(\mathrm{mg} \mathrm{L}^{-1}\right)=(A-0.00308) / 0.03908
$$

where $A$ is the UV absorbance at $240 \mathrm{~nm}$. The cumulative drug release was calculated according to the following formula:

$$
\text { Cumulative drug release } \%=M_{t} / M_{0} \times 100
$$

where $M_{t}$ is the amount of drug released from micelles at time $t$, and $M_{0}$ is the amount of drug loaded in the polymeric micelles. $M_{0}$ was estimated by subtracting the amount of unloaded drug from the feed drug amount $20 \mathrm{mg}$. The amount of unloaded drug was analyzed by measuring the absorbance of the dialyzate at $240 \mathrm{~nm}$ after drug loading. It was found that around $67.75 \mathrm{wt} \%$ of the feed drug, prednisone, was loaded into the micelles.

\section{Results and discussion}

Synthesis and characterization of PtBMA- $b$-PEG- $b$-P $t$ BMA and PMAA- $b$-PEG$b$-PMAA triblock copolymers

pH-responsive PMAA- $b$-PEG- $b$-PMAA triblock copolymers were achieved via hydrolysis of amphiphilic P $t$ BMA- $b$-PEG- $b$-P $t$ BMA triblock copolymers, while the latter was synthesized by ATRP using haloid-tailed $\mathrm{Br}-\mathrm{PEG}-\mathrm{Br}$ as a macroinitiator and $t \mathrm{BMA}$ as monomer. The $\mathrm{Br}-\mathrm{PEG}-\mathrm{Br}$ was prepared through esterification reaction of the PEG with 2-bromoisobutryl bromide, as illustrated in Scheme 1. To obtain PMAA- $b$-PEG- $b$-PMAA triblock copolymers with remarkable $\mathrm{pH}$-response, the molar ratios of the macroinitiator to monomer were controlled above 1:150, while the molar composition of macroinitiator/catalyst/ligand was tuned at 1/2/2. After the reaction was conducted at $90{ }^{\circ} \mathrm{C}$ for $24 \mathrm{~h}$, the monomer conversion was about $60 \%$.The macroinitiator, amphiphilic triblock copolymer and resulting copolymer were characterized by FT-IR, ${ }^{1} \mathrm{H}$ NMR, and GPC.

Figure 1 shows FT-IR spectra of $\mathrm{Br}-\mathrm{PEG}-\mathrm{Br}, \mathrm{P} t \mathrm{BMA}-b$-PEG- $b$-P $t \mathrm{BMA}$ and PMAA- $b$-PEG- $b$-PMAA triblock copolymers. In Fig. 1a, two strong absorption peaks at 2,886 and $1,114 \mathrm{~cm}^{-1}$ are PEG characteristic modes attributable to the $\mathrm{C}-\mathrm{H}$ and $\mathrm{C}-\mathrm{O}$ stretching vibration, and the absorption bands at 1,467 and $1,345 \mathrm{~cm}^{-1}$ belong to $\mathrm{C}-\mathrm{H}$ bending modes. Compared with the FT-IR spectra of 
Fig. 1 FT-IR spectra of (a) ATRP initiator, PEG-Br and (b) amphiphilic $\mathrm{P} t \mathrm{BMA}_{30}-b$ $\mathrm{PEG}_{45}-b-\mathrm{P} t \mathrm{BMA}_{30}$ triblock copolymer and $(c) \mathrm{pH}$-sensitive $\mathrm{PMAA}_{30}-b-\mathrm{PEG}_{45}-b$ - $\mathrm{PMAA}_{30}$ triblock polymer

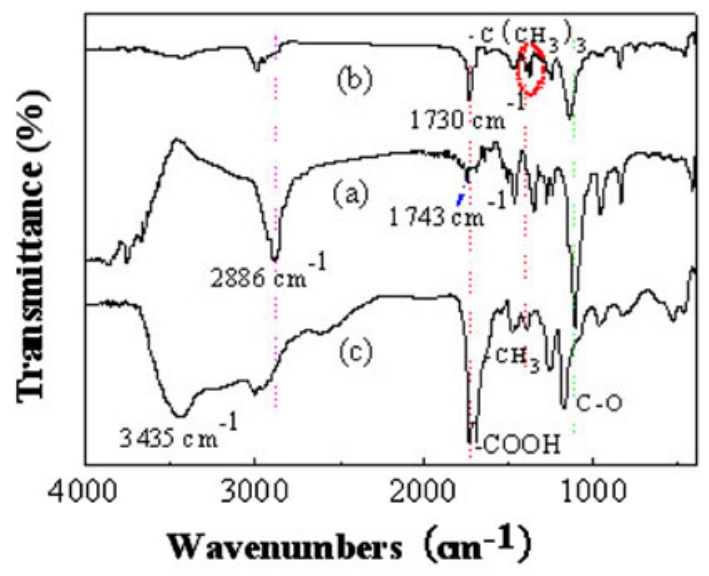

pure PEG, the emergence of the ester carbonyl $(-\mathrm{C}=\mathrm{O})$ absorption in the macroinitiator at $1,743 \mathrm{~cm}^{-1}$ and disappearance of the hydroxyl peak at $3,439 \mathrm{~cm}^{-1}$ reveal that almost all the hydroxyl groups at the PEG ends are replaced with bromide groups. The FT-IR spectra (Fig. 1b) of the P $t$ BMA- $b$-PEG- $b$ $\mathrm{Pt}$ BMA triblock copolymers exhibit the absorption peak at $1,723 \mathrm{~cm}^{-1}$ assigned to the $-\mathrm{C}=\mathrm{O}$ stretch of $\mathrm{P} t \mathrm{BMA}$ blocks which is much stronger than that of $\mathrm{Br}-\mathrm{PEG}-\mathrm{Br}$ macroinitiator. The vibration bands at $1,370-1,390 \mathrm{~cm}^{-1}$ are attributed to the $-\mathrm{C}\left(\mathrm{CH}_{3}\right)_{3}$ characteristic absorption, which is cleaved into two peaks and the peak intensity at a low wavenumber is twice as large as that at a high wavenumber, at 2,935-2,980 $\mathrm{cm}^{-1}$ assigned to the $\mathrm{C}-\mathrm{H}$ stretch modes different from that of $\mathrm{Br}-\mathrm{PEG}-\mathrm{Br}$ chains, indicating that the monomers are successfully polymerized by ATRP. In the spectra of PMAA- $b$-PEG- $b$-PMAA triblock copolymers (Fig. 1c), the wider and stronger peak between 3,000 and $3,700 \mathrm{~cm}^{-1}$ corresponds to the stretch characteristic absorption of carboxylic hydroxyl groups, and at 1,694 and $1,730 \mathrm{~cm}^{-1}$ ascribed to the carboxylic carbonyl stretch modes. Especially, the vibration bands shift to lower wavenumbers, which reflects hydrogen bonding association between $-\mathrm{COOH}$ groups, while the cleaved peaks from the $-\mathrm{C}\left(\mathrm{CH}_{3}\right)_{3}$ absorption at $1,370-1,390 \mathrm{~cm}^{-1}$ change to a single peak of the common $-\mathrm{CH}_{3}$ bending vibrations, illustrating that $\mathrm{P} t \mathrm{BMA}$ blocks have been hydrolyzed into PMAA blocks, and thus the formation of $\mathrm{pH}$-sensitive PMAA- $b$-PEG- $b$-PMAA copolymers is preliminarily proved.

${ }^{1} \mathrm{H}$ NMR spectra are further employed to verify the chemical structure of Br-PEG-Br, PtBMA- $b$-PEG- $b$-P $t$ BMA and PMAA- $b$-PEG- $b$-PMAA, as shown in the Fig. 2. The ATRP macroinitiator produces two distinct signals at $4.32 \mathrm{ppm}$ (br, $\mathrm{d}, \mathrm{CH}_{3}-\mathrm{CH}(\mathrm{Br})-$ ) and $1.83 \mathrm{ppm}\left(\mathrm{br}, \mathrm{m}, \mathrm{CH}_{3}-\mathrm{CH}(\mathrm{Br})-\right.$ ) compared to the ${ }^{1} \mathrm{H} \mathrm{NMR}$ spectra of pure PEG at $3.67 \mathrm{ppm}$ (br, m, $-\mathrm{CH}_{2} \mathrm{CH}_{2} \mathrm{O}-$ ) (Fig. 2A). In addition, the proton signal of methylene groups connected with ester groups from PEG units (br, $\left.\mathrm{m},-\mathrm{CH}_{2} \mathrm{CH}_{2}-\mathrm{OOCCH}(\mathrm{Br}) \mathrm{CH}_{3}\right)$ appears at $4.45 \mathrm{ppm}$. The esterification conversion can be estimated from the relative integral values of the signals of a and d or a:b:c:d. The ratio of a:d is close to 1.5 , while the integration area ratio of peak a:b:c:d is 
Fig. $2{ }^{1} \mathrm{H}$ NMR spectra of A ATRP initiator Br-PEG-Br in $\mathrm{CDCl}_{3}, \mathbf{B}$ amphiphilic triblock copolymer $\mathrm{P} t \mathrm{BMA}_{30}-b$ - $\mathrm{PEG}_{45^{-}}$ $b$ - $\mathrm{P} t \mathrm{BMA}_{30}$ in $\mathrm{DCCl}_{3}$ and $\mathbf{C ~ p H}-$ sensitive triblock polymer $\mathrm{PMAA}_{30}-b-\mathrm{PEG}_{45}-b-\mathrm{PMAA}_{30}$ in $d_{6}$-DMSO

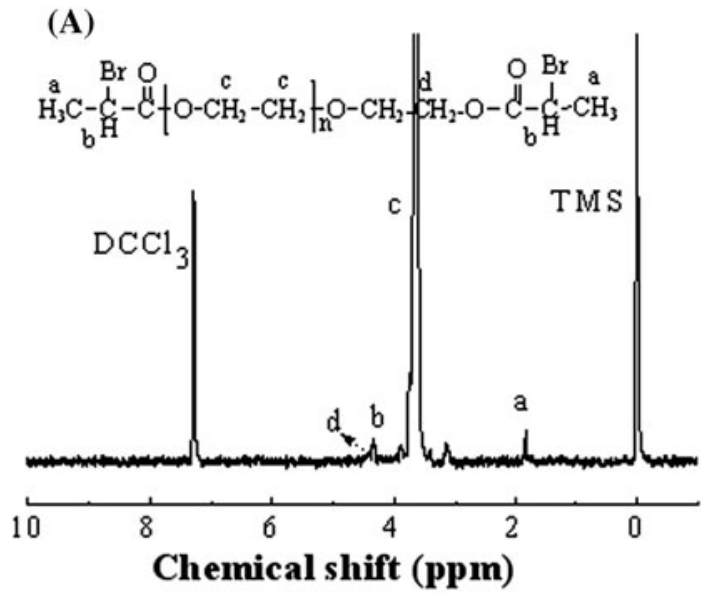

(B)

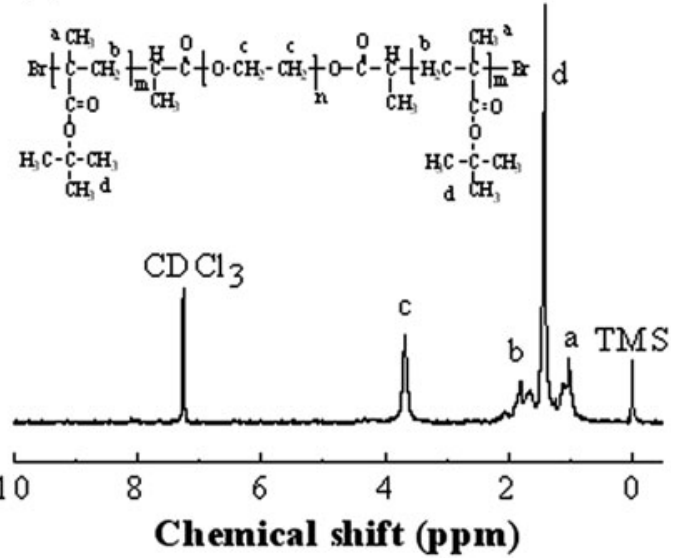

(C)

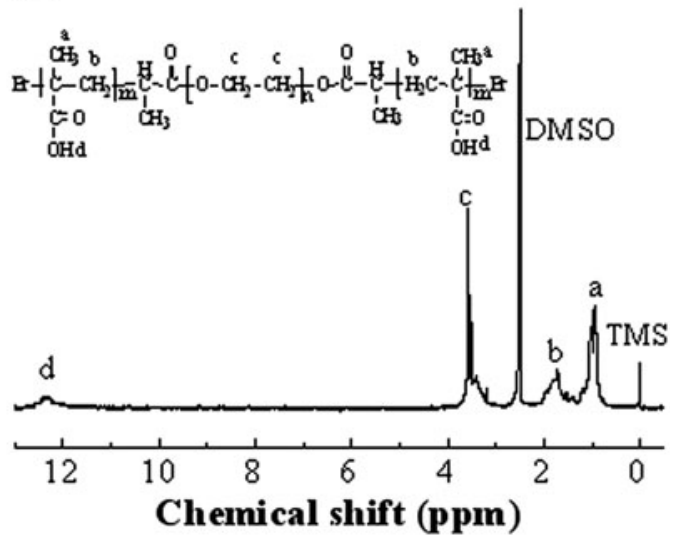


about 3:1:176:2, indicating the complete conversion of the hydroxyl group of PEG, and the successful preparation of the ATRP macroinitiator Br-PEG-Br by an esterification reaction avenue. The number-averaged molecular weight of the assynthesized macroinitiator is about 2,180 by theoretical calculation of the molecular weights of PEG and terminal residues. The characteristic shift signals (ppm) at 1.82-1.92 (signal b, br, $-\mathrm{CH}_{2} \mathrm{C}\left(\mathrm{CH}_{3}\right)$ - from PtBMA blocks), 1.04 (signal a, br, $-\mathrm{CH}_{2} \mathrm{C}\left(\mathrm{CH}_{3}\right)$ from $\mathrm{P} t \mathrm{BMA}$ side groups) and 1.42 (signal d, br, s, $-\mathrm{C}\left(\mathrm{CH}_{3}\right)_{3}$ from $\mathrm{P} t \mathrm{BMA}$ end groups) as well as the ${ }^{1} \mathrm{H}$ NMR signal of PEG at $3.67 \mathrm{ppm}$ in Fig. $2 \mathrm{~B}$ demonstrate the $t$ BMA monomer has polymerized to the P $t$ BMA- $b$-PEG- $b$-P $t$ BMA triblock copolymer. Two attractive changes in ${ }^{1} \mathrm{H}$ NMR spectra of the PMAA- $b$ PEG- $b$-PMAA triblock copolymer in Fig. $2 \mathrm{C}$, compared to the former spectra, are the occurrence of a new peak at $12.32 \mathrm{ppm}$ ascribed to the proton of carboxyl groups $(-\mathrm{COOH})$ in PMAA blocks and the disappearance of the signal at $1.42 \mathrm{ppm}$ assigned to the $-\mathrm{C}\left(\mathrm{CH}_{3}\right)_{3}$ from $\mathrm{P} t \mathrm{BMA}$. These results can strongly confirm that the P $t$ BMA- $b$-PEG- $b$-P $t$ BMA triblock copolymers are successfully hydrolyzed to PMAA- $b$-PEG- $b$-PMAA triblock polymers.

By comparing the areas of the methyl peak of the tertiary butyl group in the PtBMA units $\left(-\mathrm{C}\left(\mathrm{CH}_{3}\right)_{3}\right)$ at $\delta=1.42 \mathrm{ppm}$ and ethylene oxide units peak $\left(-\mathrm{OCH}_{2} \mathrm{CH}_{2}-\right)$ at $3.67 \mathrm{ppm}$, the number average molecular weight $\left(M_{\mathrm{n}}\right)$ of the P $t$ BMA blocks can be calculated. Similarly, the $M_{\mathrm{n}}$ of PMAA blocks can be estimated by the integration ratios of the proton signals of carboxyl groups in PMAA blocks at $12.32 \mathrm{ppm}$ to ethyoxyl resonance signals at $3.5-3.6 \mathrm{ppm}$, and the results are tabulated in Table 1. It can clearly be evolved from the NMR measurements that the $M_{\mathrm{n}}$ of the triblock copolymers is increased with increasing the monomer/initiator molar ratios whether they are amphiphilic $\mathrm{P} t \mathrm{BMA}-b$-PEG- $b$-P $t \mathrm{BMA}$ or $\mathrm{pH}$-sensitive PMAA- $b$-PEG- $b$-PMAA copolymers. After hydrolysis, the $M_{\mathrm{n}}$ values of all the polymers are decreased due to the translation of large tertiary butyl groups $\left(-\mathrm{C}\left(\mathrm{CH}_{3}\right)_{3}\right)$ in the PtBMA units into hydrogen protons. GPC data in Table 1 further corroborate the above description, and GPC traces of the macroinitiator and PtBMA$b$-PEG- $b$-P $t$ BMA triblock copolymers are shown in Fig. 3.

It is apparent that the $M_{\mathrm{n}}$ of the P $t$ BMA- $b$-PEG- $b$-P $t$ BMA block copolymer is larger than that of the macroinitiator $\mathrm{Br}-\mathrm{PEG}-\mathrm{Br}$ in that the block copolymer shows the shorter elution time, which can be regarded as an evidence of the formation of

Table 1 Sample codes, formulating of recipe, and characteristic parameters of the PtBMA- $b$-PEG- $b$ PtBMA and PMAA- $b$-PEG- $b$-PMAA triblock copolymers

\begin{tabular}{|c|c|c|c|c|c|}
\hline \multirow[t]{2}{*}{ Codes } & \multirow{2}{*}{$\begin{array}{l}\mathrm{Br}-\mathrm{PEG}_{45}-\mathrm{Br} / t \mathrm{BMA} \\
(\mathrm{mol})\end{array}$} & \multicolumn{2}{|l|}{$M_{\mathrm{n}}$} & \multirow[t]{2}{*}{$M_{\mathrm{w}}$} & \multirow[t]{2}{*}{ PDI } \\
\hline & & ${ }^{1} \mathrm{H}$ NMR & GPC & & \\
\hline $\mathrm{P} t \mathrm{BMA}_{20}-\mathrm{PEG}_{45}-\mathrm{P} t \mathrm{BMA}_{20}$ & $1 / 150$ & 10,450 & 8,040 & 11,460 & 1.43 \\
\hline $\mathrm{P} \mathrm{BMA}_{30}-\mathrm{PEG}_{45}-\mathrm{P} t \mathrm{BMA}_{30}$ & $1 / 300$ & 19,400 & 10,890 & 16,900 & 1.55 \\
\hline $\mathrm{P} t \mathrm{BMA}_{25}-\mathrm{PEG}_{90}-\mathrm{P} t \mathrm{BMA}_{25}$ & $1 / 300$ & 76,800 & 11,490 & 20,970 & 1.82 \\
\hline $\mathrm{PMAA}_{20}-\mathrm{PEG}_{45}-\mathrm{PMAA}_{20}$ & $1 / 150$ & 6,880 & 6,250 & 8,880 & 1.42 \\
\hline PMAA $_{30}-\mathrm{PEG}_{45}-\mathrm{PMAA}_{30}$ & $1 / 300$ & 11,380 & 8,120 & 11,040 & 1.36 \\
\hline $\mathrm{PMAA}_{25}-\mathrm{PEG}_{90}-\mathrm{PMAA}_{25}$ & $1 / 300$ & 11,550 & 9,300 & 10,880 & 1.17 \\
\hline
\end{tabular}


Fig. 3 GPC traces showing (a) $\mathrm{P} \mathrm{BMA}_{20}-b$ - $\mathrm{PEG}_{45}-b$ $\mathrm{P} \mathrm{BMA}_{20},(b) \mathrm{P} \mathrm{BMA}_{30}-b-$ $\mathrm{PEG}_{45}-b-\mathrm{P} t \mathrm{BMA}_{30}$, (c) $\mathrm{P} \mathrm{BMA}_{25}-b-\mathrm{PEG}_{90}-b-$ $\mathrm{P}_{t} \mathrm{BMA}_{25}$ and (d) ATRP macroinitiator $\mathrm{Br}-\mathrm{PEG}-\mathrm{Br}$ in HTF

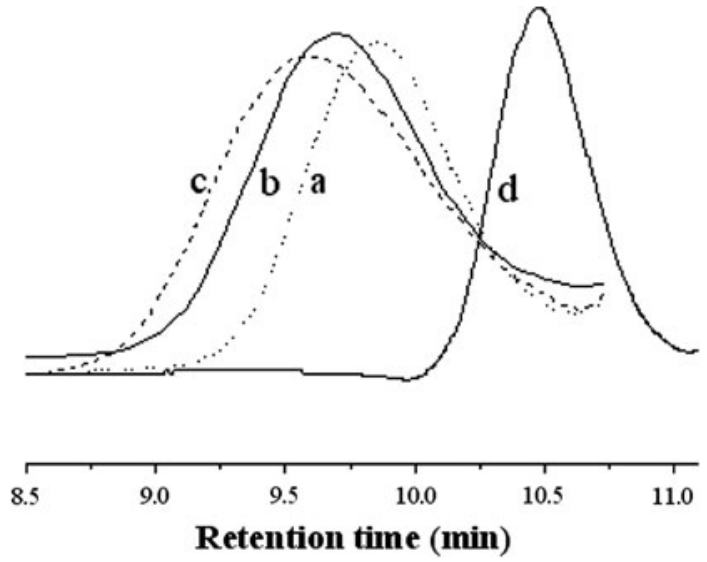

Retention time (min)

the block copolymer. With increasing the molar ratios of $t \mathrm{BMA} / \mathrm{Br}-\mathrm{PEG}_{45}-\mathrm{Br}$ or the $M_{\mathrm{n}}$ of hydrophilic PEG blocks, the $M_{\mathrm{n}}$ of the copolymers is enhanced, which is in agreement with the NMR conclusion. The GPC traces show no shoulder peak of the residual $\mathrm{Br}-\mathrm{PEG}-\mathrm{Br}$, no tailing in both lower and higher molecular weight regions, with polydispersity index of 1.10 . From the compositional ratios of $t \mathrm{BMA}$ to $\mathrm{Br}-\mathrm{PEG}_{45}-\mathrm{Br}$ or $M_{\mathrm{n}}$ values acquired by NMR and GPC, it is deduced that there are approximately 20 to $30 t \mathrm{BMA}$ or MAA units at each end of PEG chains. It is worthy to note that the $M_{\mathrm{n}}$ value determined by ${ }^{1} \mathrm{H}$ NMR is larger than that by GPC, probably due to different hydrodynamic volumes in different media. By the combination of FT-IR, ${ }^{1} \mathrm{H}$ NMR, and GPC results, it is concluded that the $t$ BMA monomers have been successfully synthesized at both ends of PEG chains, and the PMAA- $b$-PEG- $b$-PMAA has been obtained via hydrolysis of the P $t$ BMA- $b$-PEG- $b$ PtBMA.

$\mathrm{pH}$-responsive micelle formation and characterization

The PMAA- $b$-PEG- $b$-PMAA triblock copolymers are dissolvable in DMF but selfassemble into micelles in aqueous solution due to the existence of strong intra- and/ or intermolecular hydrogen bonding interactions of PMAA blocks, which aggregate in water to form the core of micelles. The CMC of the copolymer is measured by fluorescence spectroscopy using pyrene as a probe. Figure 4 depicts the excitation spectra of pyrene probe in aqueous solution of the representative $\mathrm{PMAA}_{25}-b-\mathrm{PEG}_{90^{-}}$ $b$-PMAA 25 copolymer at various concentrations. The fluorescence intensities of the excitation spectra increase with increasing the polymer concentrations, which is attributed to the increase in fluorescence quantum yield induced by the change in microenvironment surrounding the probe. The intensity ratios of pyrene $\left(I_{338} / I_{334}\right)$ are used to determine the CMC value of the triblock copolymers, as shown in Fig. 5. With the increase of the polymer concentration from 0.01 to $1,000 \mathrm{mg} \mathrm{L}^{-1}$, an abrupt increase in the plot is clearly observed, indicating that the pyrene transfers from water phase into the hydrophobic core of the micelles due to its hydrophobicity and the microenvironment of pyrene changes from high-polar water to less-polar 

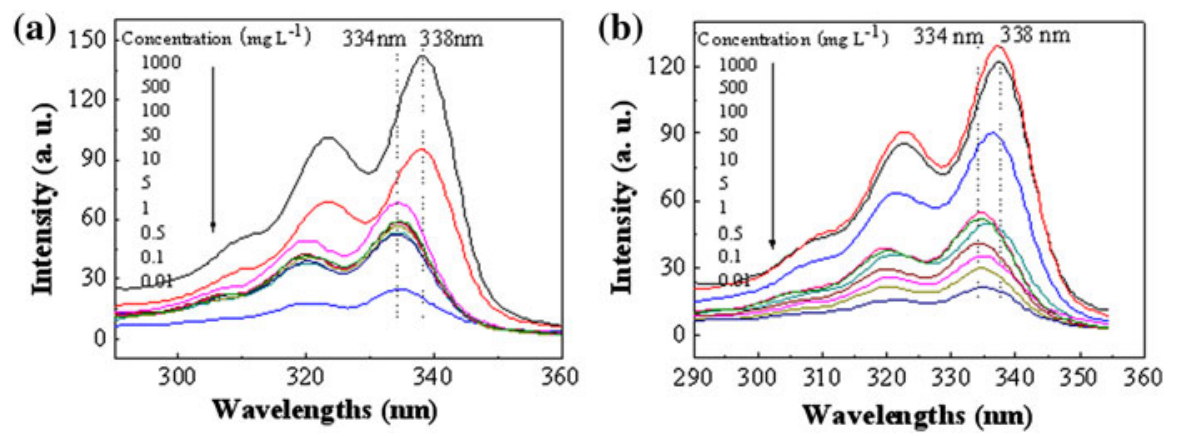

Fig. 4 Fluorescence excitation spectra of pyrene against the concentrations of the representative $\mathrm{PMAA}_{25}-b-\mathrm{PEG}_{90}-b-\mathrm{PMAA}_{25}$ copolymer micelles in aqueous (a) and PBS solutions (b)

micelle, and the CMC value is the intersection of the tangents in the Fig. 5. The CMC values of the three PMAA- $b$-PEG- $b$-PMAA triblock copolymers with different $M_{\mathrm{n}}$ of PEG chains and/or PMAA chains are listed in Table 2. The value of the $\mathrm{PMAA}_{20}-b-\mathrm{PEG}_{45}-b-\mathrm{PMAA}_{20}$ is $115.67 \mathrm{mg} \mathrm{L}{ }^{-1}$, which is bigger than the ones of the $\mathrm{PMAA}_{30}-b-\mathrm{PEG}_{45}-b-\mathrm{PMAA}_{30}$ and $\mathrm{PMAA}_{25}-b-\mathrm{PEG}_{90}-b-\mathrm{PMAA}_{25}$ copolymers, suggesting that the $\mathrm{CMC}$ value decreases with increasing the compositional ratios of hydrophilic PEG chains to PMAA chains as well as the length of hydrophilic PEG chains, where PMAA chains incline to form the core of the micelles due to the hydrophobility and complexation [25-27] originating from the intra- and/or intermolecular hydrogen bonding interactions, and hydrophilic PEG chains incline to form the shell or corona of the micelles by the back-folding and looping of PEG chains, as depicted in Scheme 2.
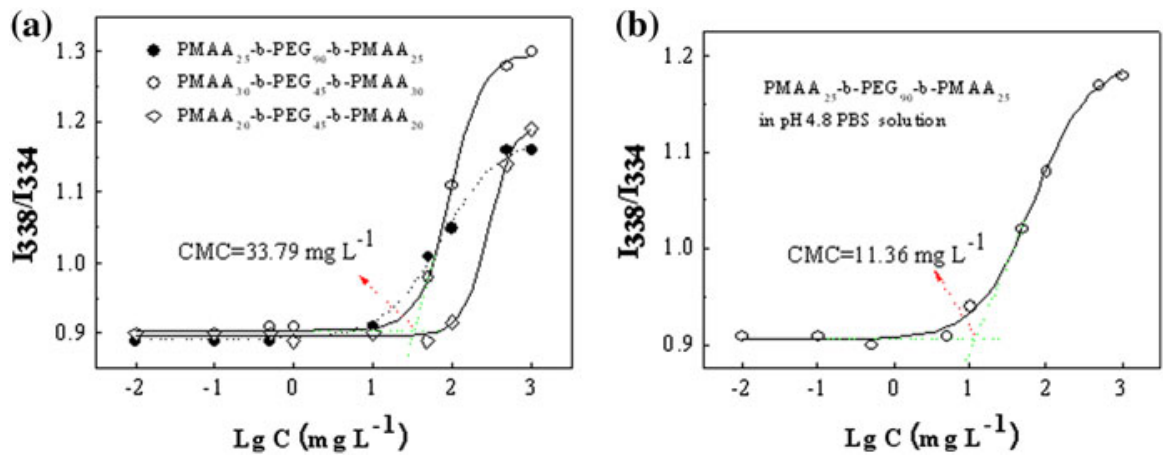

Fig. 5 Intensity ratios $I_{338} / I_{334}$ obtained from the fluorescence excitation spectra of pyrene plotted versus the copolymer concentrations at $25{ }^{\circ} \mathrm{C}$ of a PMAA $20-b-\mathrm{PEG}_{45}-b-\mathrm{PMAA}_{20}$, PMAA $30-b-\mathrm{PEG}_{45}-b-$ $\mathrm{PMAA}_{30}$, and $\mathrm{PMAA}_{25}-b-\mathrm{PEG}_{90}-b-\mathrm{PMAA}_{25}$ in aqueous solution; and b $\mathrm{PMAA}_{25}-b-\mathrm{PEG}_{90}-b-\mathrm{PMAA}_{25}$ in the PBS buffer solution of $\mathrm{pH} 4.8$ 
Table 2 Characteristic parameters of PMAA- $b$-PEG- $b$-PMAA copolymer micelles

\begin{tabular}{lcc}
\hline Copolymers & $\mathrm{CMC}\left(\mathrm{mg} \mathrm{L}^{-1}\right)^{\mathrm{a}}$ & Diameters (nm) \\
\hline $\mathrm{PMAA}_{20}-\mathrm{PEG}_{45}-\mathrm{PMAA}_{20}$ & 115.67 & 75.46 \\
$\mathrm{PMAA}_{30}-\mathrm{PEG}_{45}-\mathrm{PMAA}_{30}$ & 33.79 & 72.34 \\
$\mathrm{PMAA}_{25}-\mathrm{PEG}_{90}-\mathrm{PMAA}_{25}$ & 13.18 & 118.38 \\
\hline
\end{tabular}

${ }^{\text {a }} \mathrm{CMC}$ values were determined by means of the fluorescence spectroscopy using pyrene as a probe.

${ }^{b}$ Determined by DLS, and the concentration of the triblock copolymer micelles in aqueous solution is $100 \mathrm{mg} \mathrm{L}^{-1}$

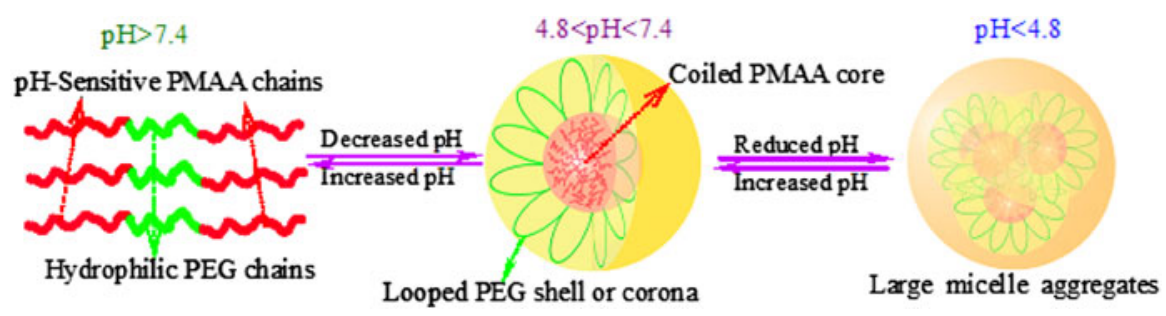

Scheme 2 Schematic representation of a $\mathrm{pH}$-response triblock copolymer micelle in aqueous media with various $\mathrm{pH}$ values

The self-assembly micellization behavior of the as-synthesized triblock copolymers in PBS solutions with $\mathrm{pH} 4.8$ and 7.4 were also investigated to understand the micelle stability in stimulated bodily environments for drug delivery applications, and the results are illustrated in Fig. 5b. Actually, the $\mathrm{pH}$ has apparent effect on the micellization behavior of the block copolymer. In acidic PBS solutions with $\mathrm{pH} 4.8$ $(<5.5)$, PMAA blocks, which has $\mathrm{p} K_{\mathrm{a}}$ of about 5.6, can form intra- and/or intermolecular hydrophobic interactions due to protonation of polycarboxylate anions of PMAA [28], and thus still show hydrophobicity, resulting in a slightly decreased CMC value. In particular, a complexation between carboxylic groups and ethylene oxide repeat units may play an important role in the micelle formation. It is well known that the interpolymer complexation is the non-covalent association between groups on different polymer chains, which forms due to thermodynamical compatibility of polymers based on van der Waals interactions, polyelectrolyte association and hydrogen bonding [25]. In the case of PMAA with electron deficient groups and PEG containing regions of high electron density, interpolymer complexes or the complexation are apt to form due to the collapse of macromolecular chains induced by the PMAA chains contracting and the enhanced association between PMAA and PEG chains based on the formation of hydrogen bonds. The PMAA complexes are more stable than those involving poly(acrylic acid) due to hydrophobic stabilization of the hydrogen bonds by the $\alpha$-methyl group. Gohy [26] considered that the driving force for micelle formation in these copolymers is the self-complexation between PEO/PEG and PMAA blocks due to hydrogen bonding. All these make the copolymer micelles more easily form. Hence, the as-prepared block copolymer micelles have better stability in the simulated physiological environments of $\mathrm{pH} 4.8$. However, at $\mathrm{pH} 7.4$, the $\mathrm{CMC}$ value can not 

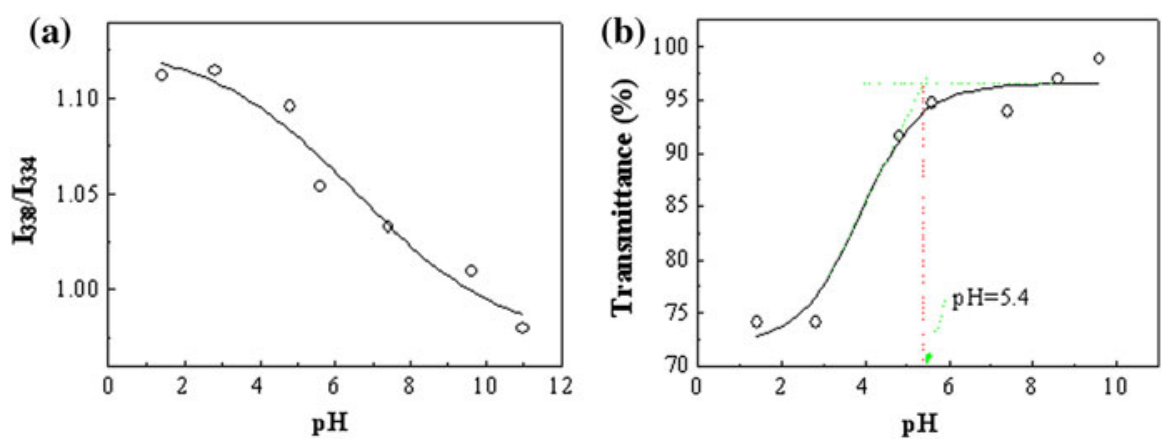

Fig. 6 Fluorescence intensity ratios $I_{338} / I_{334}$ from pyrene excitation spectra (a) and UV-Vis transmittance at $500 \mathrm{~nm}$ (b) of the representative $\mathrm{PMAA}_{25}-b-\mathrm{PEG}_{90}-b-\mathrm{PMAA}_{25}$ micelles as a function of $\mathrm{pH}$ values (the concentration is $100 \mathrm{mg} \mathrm{L}^{-1}$ )

be available because of gradual ionization of $-\mathrm{COOH}$ groups in PMAA blocks, which cause micellar unstability and dissociation of the core-shell structure. This is meaningful for releasing the enclosed drug molecules [7-9]. It follows that PMAA$b$-PEG- $b$-PMAA copolymer exhibits $\mathrm{pH}$-responsive property, as expected. Figure 6 illustrates $I_{338} / I_{334}$ intensities and transmittance changes of the copolymers at wavelength of $500 \mathrm{~nm}$ with $\mathrm{pH}$. In this figure, it can be seen that the PMAA- $b$-PEG$b$-PMAA triblock copolymers show a sharp transition behavior at ca. $\mathrm{pH} 5.4$, which is very close to the $\mathrm{p} K_{\mathrm{a}}$ (about 5.6) of PMAA blocks. Below this value, nonionized PMAA assumes a hypercoiled conformation, and the copolymers are apt to form the aggregate micelles due to the intramolecular hydrogen bonding of the MAA units resulting from protonation of PMAA moieties [29]. In the neighborhood of the $\mathrm{p} K_{\mathrm{a}}$, the triblock copolymers start to experience the structure transition from large aggregates to self-assembled micelles. When $\mathrm{pH}$ of the solution is increased above 7.4, PMAA- $b$-PEG- $b$-PMAA chains are in extended chain conformation due to the electrostatic repulsion between the PMAA segments after deprotonation of PMAA blocks [30], and the solution becomes transparent, and the micelles are dissociated into unimers. Therefore, the same conclusion that the triblock copolymer micelles exhibit pH-response can be inferred from the decrease in the $I_{338} / I_{334}$ intensities (Fig. 6a) and the increase in the transmittance (Fig. 6b).

The formation of $\mathrm{pH}$-dependent micelles from the double-hydrophilic PMAA- $b$ PEG- $b$-PMAA triblock copolymer is further verified by DLS experiments carried out in aqueous and various $\mathrm{pH}$ PBS solutions at $25^{\circ} \mathrm{C}$ with concentration of $100 \mathrm{mg}$ $\mathrm{L}^{-1}$, as shown in Fig. 7. The DLS hydrodynamic radius $\left(R_{\mathrm{h}}\right)$ or diameter $\left(D_{\mathrm{h}}\right)$ varies with $\mathrm{pH}$. At low $\mathrm{pH}(<4.8)$, the polymer chains aggregate into larger particles resembling that of a hard sphere induced by the intra- and/or intermolecular hydrogen bonding interactions of PMAA blocks as well as the complexation based on the hydrogen bonds between carboxyl groups in PMAA blocks and ether oxygen atoms from PEG blocks. Since the degree of complexation between PAA and PEO increases with decreasing the $\mathrm{pH}$ value [27], as reported by $\mathrm{Li}$ and Chen via an enhanced Rayleigh scattering spectroscopy (ERS) combined with the moving 
Fig. 7 Size change of the $\mathrm{PMAA}_{25}-b-\mathrm{PEG}_{90}-b$ - $\mathrm{PMAA}_{25}$ micelles as a function of $\mathrm{pH}$ at $25^{\circ} \mathrm{C}$ as measured by DLS (the concentration of the copolymers is $100 \mathrm{mg} \mathrm{L}^{-1}$ )

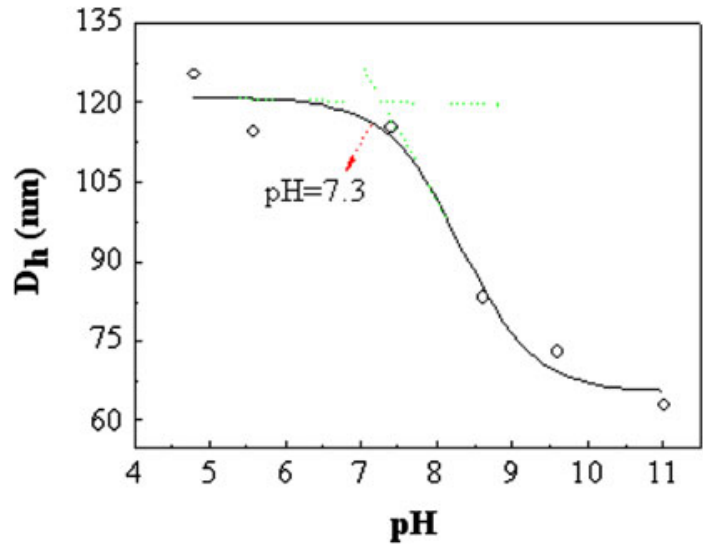

window two-dimensional (MW2D) correlation spectroscopy, it is not hard to understand that the existence of larger aggregates at low $\mathrm{pH}$ values may predominantly be influenced by a high degree of the complexation, which leads to the precipitation of the polymer micelles from water. At moderate $\mathrm{pH}$ values, for example, $4.8<\mathrm{pH}<7.4$, core-shell micelles are steadily formed based on the reasonable complexation stabilization and/or hydrophobic stabilization of the hydrogen bonds with partially protonated MAA core, and the middle PEG blocks self-assemble into micellar corona due to the back-folding and looping of PEG chains $[25,29,31]$. At high $\mathrm{pH}(>7.4)$, PMAA units are gradually ionized, the coreshell micelles with water-soluble PMAA core and hydrophilic PEG loop chain corona are constructed. The change in the $\mathrm{pH}$ would cause the conformation change of PMAA segments from extended chain to hypercoil, and vice versa, which in turn results in the aggregation of PMAA chain segments into micellar cores. Thereby, the micelle of the triblock copolymers is extremely $\mathrm{pH}$-sensitive and controllable by the macroinitiator PEG/tBMA compositional ratios, the $M_{\mathrm{n}}$ of PEG and $\mathrm{pH}$ of the media.

\section{Morphologies and size distribution}

The uptake characteristics of drugs encapsulated in the micelles will be affected by the morphologies and the size of the particles. It is important for polymer micelles as drug carriers to bear the size smaller than $<200 \mathrm{~nm}$ for their biomedical applications since the polymer micelles can avoid glomerular filtration of human bodies for their biomedical applications. Simultaneously, since the blood vessels in tumor tissues possess enhanced permeability and retention (EPR), small diameters of particles from polymer micelles (10-200 nm) make for their retention and congeries in tumor tissues, and thus endow them with passive targeting function to tumor tissues [32]. Therefore, the morphologies, size, and size distribution of the representative $\mathrm{PMAA}_{25}-b-\mathrm{PEG}_{90}-b$ - $\mathrm{PMAA}_{25}$ triblock copolymer micelles in aqueous solution and PBS buffer solutions with $\mathrm{pH}$ of 4.8 and 7.4 are investigated by TEM observations and DLS measurements, as depicted in Fig. 8. 

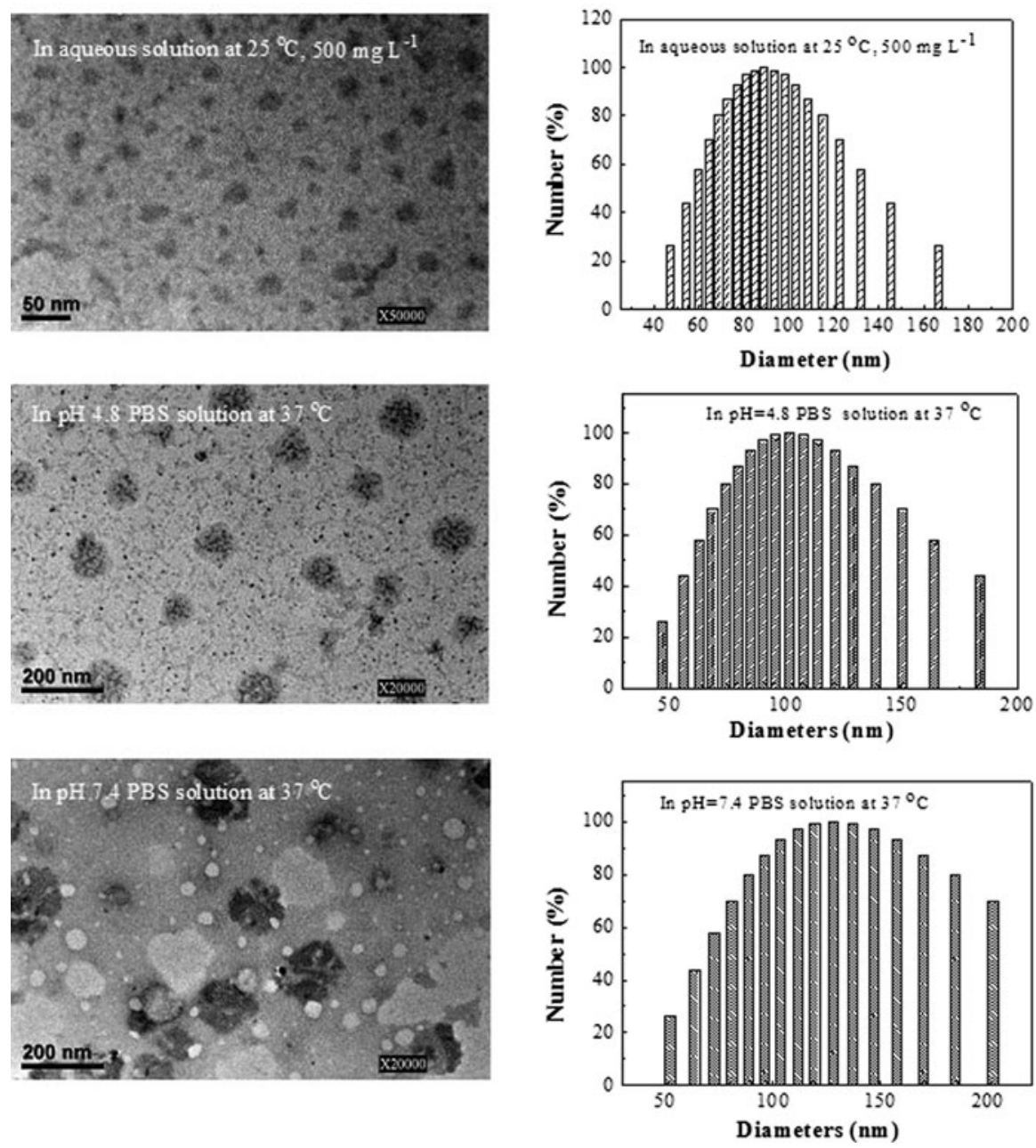

Fig. 8 TEM images and hydrodynamic diameter distributions of micelles formed from PMAA $25-b$ $\mathrm{PEG}_{90^{-}} b-\mathrm{PMAA}_{25}$ in aqueous solution (the concentration of the copolymer micelles is $500 \mathrm{mg} \mathrm{L}^{-1}$ ) and simulated physiological media (the concentration of the copolymer micelles is $100 \mathrm{mg} \mathrm{L}^{-1}$ )

Figure 8 demonstrates that the $\mathrm{PMAA}_{25}-b-\mathrm{PEG}_{90}-b-\mathrm{PMAA}_{25}$ triblock copolymers (concentration: $500 \mathrm{mg} \mathrm{L}^{-1}$ ) self-assemble and form micelles with almost spherical shapes in aqueous solution. The micelles bear narrow size distribution with the size range from around 10 to $25 \mathrm{~nm}$, and an average diameter of around $18 \mathrm{~nm}$. DLS measurements give the same conclusion that the hydrodynamic diameter $\left(D_{\mathrm{h}}\right)$ or radius $\left(R_{\mathrm{h}}\right)$ distribution is much narrow in aqueous solution at room temperature with the range from 47 to $167 \mathrm{~nm}$ centered at $89 \mathrm{~nm}$. When the concentration is $100 \mathrm{mg} \mathrm{L}^{-1}$, the corresponding mean size is approximately $118.40 \mathrm{~nm}$, larger than that at a $500 \mathrm{mg} \mathrm{L}^{-1}$ micelle solution (Table 2). This 
concentration dependence may be ascribed to stronger intermicellar hydrophobic associations in a highly concentrated solution, which more easily leads to phase separation and form micelles with small size. For the three PMAA- $b$-PEG- $b$-PMAA triblock copolymers, the micellar size is decreased with increasing the compositional ratios of the $t \mathrm{BMA} / \mathrm{Br}-\mathrm{PEG}-\mathrm{Br}$ and reducing the $M_{\mathrm{n}}$ of PEG. It is clear that the size is far less than the micelle dimension required as drug carriers for their biomedical applications. It is interesting to note that the size observed by TEM is obviously smaller than that detected by DLS. The difference may be attributed to the fact that the micelles experience the dehydration step during the sample preparation for TEM measurements. Thus, the TEM reveals the morphological size of the micelles in the solid state, while the DLS reflects the hydrodynamic diameter of the micelles in aqueous solutions.

Furthermore, the $\mathrm{pH}$-dependent morphologies, $D_{\mathrm{h}}$ and size distribution of the triblock copolymer (concentration: $100 \mathrm{mg} \mathrm{L}^{-1}$ ) in two simulated physiological environments $\left(37^{\circ} \mathrm{C}, \mathrm{pH} 4.8\right.$ and 7.4) are investigated, as displayed in Fig. 8. It can be seen that the $\mathrm{PMAA}_{25}-b-\mathrm{PEG}_{90}-b$ - $\mathrm{PMAA}_{25}$ triblock copolymer forms welldefined spherical micelles in $\mathrm{pH} 4.8$ and 7.4 PBS solutions at $37{ }^{\circ} \mathrm{C}$, and the micelle size distribution is around 50-185 and 50-200 nm, centered at 102 and $128 \mathrm{~nm}$, respectively, indicating that the triblock copolymer micelles are thermodynamically stable in a diluted PBS phase, and that they can easily be used in the systematic circulation through intravenous injection into a large number of blood. The gradually broadened size distribution and significantly enhanced micelle $D_{\mathrm{h}}$ may be associated with the increased hydrophilicity due to the gradual ionization of PMAA with increasing $\mathrm{pH}$. In this case, a part of the $\mathrm{PMAA}_{25}-b$ - $\mathrm{PEG}_{90}-b$ - $\mathrm{PMAA}_{25}$ triblock copolymer chains are in extended chain conformation due to the electrostatic repulsion between the PMAA segments, while the other PMAA chain segments aggregate into micellar cores as result of the intramolecular hydrogen bonding of the MAA units [29]. It can be inferred that the triblock copolymer micelles are pHsensitive and significative for dissociation and release of the enclosed drug molecules in different $\mathrm{pH}$ environments.

\section{Cytotoxicity studies}

Cytotoxicity is one of the major barriers in in vitro and/or in vivo applications for biomaterials, and ideal biomaterials should not release toxic products or produce adverse reactions. In our work, an in vitro cytotoxicity study was carried out to evaluate the biocompatibility of the $\mathrm{pH}$-sensitive triblock copolymers by MTT assay, which is used as a measure of relative cell viability in contact with the polymer extract solution. Figure 9 displays the effect of various copolymer concentrations after different incubation intervals on the viable rate or proliferation of L929 mouse embryonic fibroblasts. It is seen that the resultant copolymer micelles does not show significant cytotoxicity to L929 cells below $400 \mathrm{mg} \mathrm{L}^{-1}$ of the polymer micellar concentrations, with the cell viability more than $76 \%$ after $24 \mathrm{~h}$ incubation $(p<0.05)$. The slight cytotoxicity may be ascribed to the incorporation of the biocompatible PEG blocks into the architecture. Above $800 \mathrm{mg}$ $\mathrm{L}^{-1}$, however, the moderate cytotoxicity produces with the cell viability lower than 
(a)

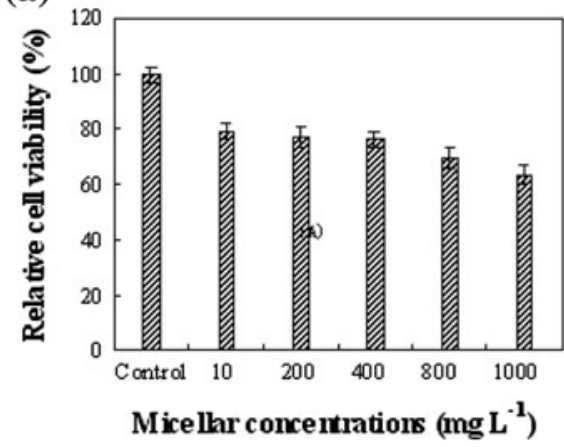

(b)

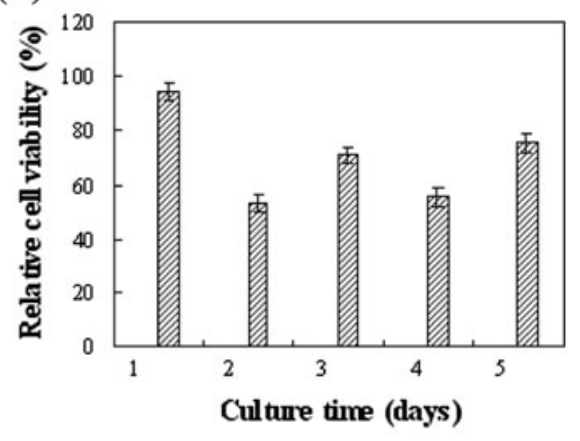

Fig. 9 Cytotoxicity to L929 cells of the $\mathrm{PMAA}_{25}-b-\mathrm{PEG}_{90}-b-\mathrm{PMAA}_{25}$ copolymer micelles at different polymer concentrations after $24 \mathrm{~h}$ incubation determined by MTT assay. Cells treated with culture media only were taken as the $100 \%$ viability. Each point represents the mean \pm SD of four experiments

$70 \%$. Therefore, the triblock copolymer micelles have generally low cytotoxicity to the L929 cells at the micellar concentration below $400 \mathrm{mg} \mathrm{L}^{-1}$, and can be employed as potential candidates for future specific drug release applications.

Controlled drug release from $\mathrm{pH}$-sensitive triblock copolymer micelles

Hydrophobic drugs can be loaded into the micelles due to the hydrophobic core of the micelles. Prednisone, an anti-inflammatory drug with a very low solubility in water, was employed as a model drug to evaluate the controlled release properties of the $\mathrm{PMAA}_{25}-b-\mathrm{PEG}_{90}-b-\mathrm{PMAA}_{25}$ triblock copolymer micelles. The controlled drug release behavior is measured in distilled water and PBS solution with $\mathrm{pH}$ of 7.4, and the release patterns are shown in Fig. 10. It is evident that the profile of drug release shows drastic changes at the onset of the release in different media. In particular, the hydrophobic drug encapsulated can be more rapidly released at $\mathrm{pH} 7.4$ buffer solution because the micelle core has become more hydrophilic, even dissociated,

Fig. $10 \mathrm{pH}$-sensitive release behavior of the prednisone drug loaded $\mathrm{PMAA}_{30}-b-\mathrm{PEG}_{45}-b$ $\mathrm{PMAA}_{30}$ copolymer micelles in deionized water and at $\mathrm{pH}$ of 7.4

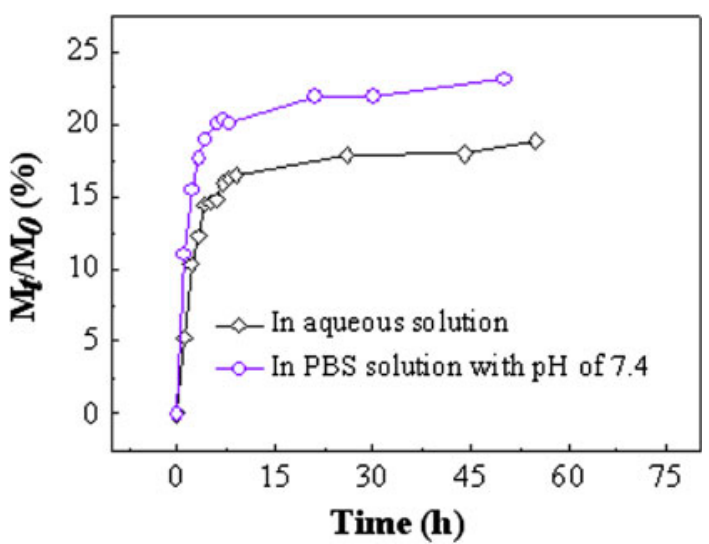


due to partial ionization in the simulated physiological environments. The drug continues to be released from the micelles during the following operation, and the release rate in the PBS solution of $\mathrm{pH} 7.4$ is still greater than that in aqueous solution. Considering $\mathrm{pH}$ ranges in some therapeutic targets such as tumors, and inflammation or ischemia sites from 5.7 to 7.8 [7-9], as well as faster release rates in $\mathrm{pH}$ 7.4 PBS solution, the as-synthesized triblock copolymer micelles are suitable for pH-response drug carriers.

Kinetic study of drug release is often useful in obtaining physically meaningful parameters for comparative purposes and relating some release parameters such as bioavailability. These kinetic parameters can further be employed to study the influence of various factors, such as formulation and release environments, on the drug release for optimization as well as control of release [33]. Therefore, one of the objectives of this contribution is to elucidate the drug transport mechanism involved in the release of a drug from the micelles.

To well apprehend the $\mathrm{pH}$-triggered hydrophobic drug release behavior, the Ritger-Peppas model [34-36] is considered to elucidate the prednisone drug transport mechanism from the $\mathrm{PMAA}_{25}-b-\mathrm{PEG}_{90}-b-\mathrm{PMAA}_{25}$ micelle by fitting these kinetic data for the onset stage of drug release (the model is valid only for the first $60 \%$ of the fractional release):

$$
\begin{gathered}
M_{t} / M_{\infty}=k t^{n} \\
\ln \left(M_{t} / M_{\infty}\right)=\ln (k)+n \ln (t)
\end{gathered}
$$

where $M_{t}$ and $M_{\infty}$ are the total amount of drug released at time $t$ and equilibrium time, respectively. $k$ is a kinetic constant that measures the drug release rate and is calculated by measuring the intercepts of the lines by the least squire method. $n$ represents an exponent characteristic of the release mechanism. When $n$ is less than or equal to 0.5 , the drug release is controlled by Fickian diffusion mechanism. When the value is between 0.5 and 1, an anomalous diffusion occurs. Drug release follows a diffusion mechanism approaching zero-order release as the $n$ value equals to 1 . This model can be considered as a general model for drug release kinetics from nanosystems, slabs, spheres, cylinders, and discs (tablets), regardless of the release mechanism.

Based on this description, linear-regression analyses on the drug release versus release time from Fig. 10 are carried out, and the relevant formulas of the regression relations are set up, as shown in Table 3. It can be seen that the $n$ value is larger than 0.5 in the aqueous solution at $25^{\circ} \mathrm{C}$, implying that the prednisone release in the micelles deviates from the Fickian diffusion control mechanism, the drug transport mechanism appears to be anomalous. While in PBS solution of $\mathrm{pH} 7.4\left(37^{\circ} \mathrm{C}\right)$, the

Table 3 Regression equations and kinetic parameters obtained from fitting drug release experimental data to Ritger-Peppas model

\begin{tabular}{llllr}
\hline Temperature $\left({ }^{\circ} \mathrm{C}\right)$ & Regression equation & $R^{2}$ & $n$ & $\ln (k)$ \\
\hline 25 (aqueous solution) & $y=0.6423 x-2.8475$ & 0.9419 & 0.6423 & -2.8475 \\
37 (pH 7.4) & $y=0.3943 x-2.1779$ & 0.9808 & 0.3943 & -2.1779 \\
\hline
\end{tabular}


Table 4 Prednisone diffusion coefficients calculated with the early-time and late-time approximation release equations at 25 and $37^{\circ} \mathrm{C}$

\begin{tabular}{|c|c|c|c|c|c|}
\hline Temperature $\left({ }^{\circ} \mathrm{C}\right)$ & $R^{2}$ & $\begin{array}{l}D_{\mathrm{E}} \\
\left(\mathrm{cm}^{2} \mathrm{~s}^{-1}\right) \times 10^{-5}\end{array}$ & Temperature $\left({ }^{\circ} \mathrm{C}\right)$ & $R^{2}$ & $\begin{array}{l}D_{\mathrm{L}} \\
\left(\mathrm{cm}^{2} \mathrm{~s}^{-1}\right) \times 10^{-14}\end{array}$ \\
\hline $\begin{array}{l}25 \text { (aqueous } \\
\text { solution) }\end{array}$ & 0.9691 & 1.74 & $\begin{array}{l}25 \text { (aqueous } \\
\text { solution) }\end{array}$ & 0.9496 & 7.66 \\
\hline 37 (pH 7.4) & 0.9146 & 6.70 & $37(\mathrm{pH} 7.4)$ & 0.9345 & 12.7 \\
\hline
\end{tabular}

drug release is primarily controlled by the Fickian diffusion in the case of $n$ of 0.3943. Drug transport mechanism analyses further reveal that the drug release behavior may be mediated by the structural changes of the micelles as well as the environment-induced diffusion.

In order to deeply study the drug release kinetics in the micelles in different media, mathematical analysis of the prednisone release kinetics from $\mathrm{PMAA}_{25}-b$ $\mathrm{PEG}_{90}-b-\mathrm{PMAA}_{25}$ copolymer micelles in different media is performed by calculating the diffusion coefficients, $D_{\mathrm{E}}$ and $D_{\mathrm{L}}$ using the early-time (Eq. 6) and late-time (Eq. 7) approximation equations, respectively [37].

$$
\begin{gathered}
M_{t} / M_{\infty}=\left(4 D_{\mathrm{E}} / \delta \pi^{0.5}\right) t^{0.5} \\
M_{t} / M_{\infty}=1-\left(8 / \pi^{2}\right) \exp \left[-\left(\pi^{2} D_{\mathrm{L}} t\right) / \delta^{2}\right] \\
\ln \left(\pi^{2} / 8\right)\left(1-M_{t} / M_{\infty}\right)=-\left(\pi^{2} D_{\mathrm{L}} / \delta^{2}\right) t
\end{gathered}
$$

where $M_{t} / M_{\infty}$ is the fractional drug release, $t$ is the release time, $D_{\mathrm{E}}$ and $D_{\mathrm{L}}$ are the corresponding diffusional coefficients and $\delta$ is the diffusional distance. In the case of spherical PMAA ${ }_{25}-b-\mathrm{PEG}_{90^{-}} b$ - $\mathrm{PMAA}_{25}$ copolymer micelles, it is about $4.8 \times 10^{-6}$, and $6.4 \times 10^{-6} \mathrm{~cm}$ in aqueous solution at $25^{\circ} \mathrm{C}$, and in $\mathrm{pH}$ of 7.4 at $37^{\circ} \mathrm{C}$, respectively. Drug release data in Fig. 10 are fitted to the early-time and late-time approximation equations by plotting $M_{t} / M_{\infty}$ versus $t^{0.5}$ and $\log \left(\pi^{2} / 8\right)\left(1-M_{t} / M_{\infty}\right)$ versus $t$, and the corresponding diffusion coefficients $D_{\mathrm{E}}$ and $D_{\mathrm{L}}$ are calculated, respectively, as shown in Table 4. It is clear that the micelles exhibit higher prednisone diffusion coefficients in $\mathrm{pH}$ of 7.4 at $37{ }^{\circ} \mathrm{C}$ than in aqueous solution at $25{ }^{\circ} \mathrm{C}$ in both early-time and late-time approximation equations. It is worthy to note that $D_{\mathrm{L}}$ values are always lower than $D_{\mathrm{E}}$ ones at both the cases, indicating that drug release rates decrease with the release time, which is in agreement with the prednisone release profiles. The preliminary kinetic modeling confirms that the copolymer micelles prepared in our work as a drug release carrier can control drug release behavior and improve bioavailability in different media.

\section{Conclusion}

In summary, $\mathrm{pH}$-response PMAA- $b$-PEG- $b$-PMAA triblock copolymers have been synthesized via esterification, ATRP and hydrolysis routes, as revealed by FT-IR, ${ }^{1} \mathrm{H}$ NMR, and GPC. These copolymers can self-assemble into nanolevel micelles 
with the $\mathrm{pH}$-sensitive PMAA blocks as cores and the PEG segments as hydrophilic shells or coronas in various media values via inter- and/or intramolecular hydrophobic and/or hydrogen bonding interactions, as disclosed by UV-Vis transmittance, fluorescence and DLS measurements. The copolymer micelles are almost spherical shapes in aqueous solution with an average size range from 18 to $89 \mathrm{~nm}$, depending on the micellar concentrations, while they assume well-defined spherical morphologies in moderate PBS solutions. The CMC values decrease with the increase of the length or molecular weights of PEG and PMAA chains as well as $\mathrm{pH}$ values. The micelles can encapsulate prednisone in the micellar core, with encapsulation efficiency of $67.75 \%$. The results imply that it is more favorable for the triblock copolymer micelles to encapsulate hydrophobic drug in aqueous solution, and deliver them above $\mathrm{pH}$ of 7.4, which shows the potential use of PMAA- $b$-PEG- $b$-PMAA micelle system for the small intestine-targeted delivery of various hydrophobic drugs. These triblock copolymers are generally low cytotoxicity at a micellar concentration below $400 \mathrm{mg} \mathrm{L}^{-1}$, as revealed by the MTT assay. Therefore, the $\mathrm{pH}$-sensitive polymeric micelles can be used as good drug carrier candidates for the specific biomedical applications.

Acknowledgments This work is supported by the Natural Science Foundation of China (Grant NSFC21072124), Natural Science Foundation of Shaanxi Province (2012JM6009), and Graduate Education Innovation Funds (2012CXS043).

Open Access This article is distributed under the terms of the Creative Commons Attribution License which permits any use, distribution, and reproduction in any medium, provided the original author(s) and the source are credited.

\section{References}

1. Lee H, Pietrasikb J, Sheikoc SS, Matyjaszewskid K (2010) Stimuli-responsive molecular brushes. Prog Polym Sci 35(1-2):24-44

2. Meng F, Zhong Z, Feijen J (2009) Stimuli-responsive polymersomes for programmed drug delivery. Biomacromolecules 10(2):197-209

3. Soma CE, Dubernet C, Barratt G, Nemati F, Appel M, Benita S, Couvreur P (1999) Ability of doxorubicin-loaded nanoparticles to overcome multidrug resistance of tumor cells after their capture by macrophages. Pharm Res 16(11):1710-1716

4. Wei H, Cheng SX, Zhang XZ, Zhuo RX (2009) Thermo-sensitive polymeric micelles based on poly(N-isopropylacrylamide) as drug carriers. Prog Polym Sci 34(9):893-910

5. You YZ, Oupicky D (2007) Synthesis of temperature-responsive heterobifunctional block copolymers of poly(ethylene glycol) and poly(N-isopropylacrylamide). Biomacromolecules 8(1):98-105

6. Kozlovskaya V, Kharlampieva E, Khanal BP, Manna P, Zubarev ER, Tsukruk VV (2008) Ultrathin layer-by-layer hydrogels with incorporated gold nanorods as $\mathrm{pH}$-sensitive optical materials. Chem Mater 20(24):7474-7485

7. Soppimath KS, Tan DCW, Yang YY (2005) pH-Triggered thermally responsive polymer core-shell nanoparticles for drug delivery. Adv Mater 17(3):318-323

8. Eun SL, Hyun JS, Na K, Bae YH (2003) Poly(L-histidine)-PEG block copolymer micelles and pHinduced destabilization. J Control Release 90(3):363-374

9. Lee ES, Na K, Bae YH (2003) Polymeric micelle for tumor $\mathrm{pH}$ and folate-mediated targeting. J Control Release 91(1-2):103-113

10. Peppas NA, Keys KB, TorresLugo M, Lowman AM (1999) Poly(ethylene glycol)-containing hydrogels in drug delivery. J Control Release 62(1-2):81-87 
11. Jones MC, Leroux JC (1999) Polymeric micelles-a new generation of colloidal drug carriers. Eur J Pharm Biopharm 48(2):101-111

12. Gaucher G, Dufresne MH, Sant VP, Kang N, Maysinger D, Leroux JC (2005) Block copolymer micelles: preparation, characterization and application in drug delivery. J Control Release 109(1-3):169-188

13. Du JZ, Tang LY, Song WJ, Shi Y, Wang J (2009) Evaluation of polymeric micelles from brush polymer with poly( $\varepsilon$-caprolactone)-b-poly(ethyleneglycol) side chains as drug carrier. Biomacromolecules 10(8):2169-2174

14. Xiong DA, He ZP, An YL, Li Z, Wang H, Chen X, Shi LQ (2008) Temperature-responsive multilayered micelles formed from the complexation of PNIPAM- $b$-P4VP block-copolymer and PS- $b$ PAA core-shell micelles. Polymer 49(10):2548-2552

15. Zhang L, Eisenberg A (1995) Multiple morphologies of "crew-cut" aggregates of polystyrene-bpoly(acrylic acid) block copolymers. Science 268(5218):1728-1731

16. Wang JS, Matyjaszewski K (1995) Controlled/“living" radical polymerization-atom transfer radical polymerization in the presence of transition-metal complexes. J Am Chem Soc 117(20):5614-5615

17. Jakubowski W, Tsarevsky NV, Higashihara T, Faust R, Matyjaszewski K (2008) Allyl halide (macro) initiators in ATRP: synthesis of block copolymers with polyisobutylene segments. Macromolecules 41(7):2318-2323

18. Ranganathan K, Deng R, Kainthan RK, Wu C, Brooks DE, Kizhakkedathu JN (2008) Synthesis of thermoresponsive mixed arm star polymers by combination of RAFT and ATRP from a multifunctional core and its self-assembly in water. Macromolecules 41(12):4226-4234

19. Gao H, Matyjaszewski K (2007) Low-polydispersity star polymers with core functionality by crosslinking macromonomers using functional ATRP initiators. Macromolecules 40(3):399-401

20. Hofland HEJ, Masson C, Iginla S, Osetinsky I, Reddy JA, Leamon CP, Scherman D, Bessodes M, Wils P (2002) Folate-targeted gene transfer in vivo. Mol Ther 5(6):739-744

21. Shin J, Shum P, Thompson DH (2003) Acid-triggered release via dePEGylation of DOPE liposomes containing acid-labile vinylether PEG-lipids. J Control Release 91(1-2):187-200

22. Sun Y, Peng Z, Liu X, Tong Z (2010) Synthesis and pH-sensitive micellization of doubly hydrophilic poly(acrylic acid)-b-poly(ethylene oxide)-b-poly(acrylic acid) triblock copolymer in aqueous solutions. Colloid Polym Sci 288(9):997-1003

23. Tao YH, Liu R, Liu XY, Chen MQ, Yang C, Ni ZB (2009) pH-Sensitive micelles based on doubleHydrophilic poly(methylacrylic acid)-poly(ethylene glycol)-poly(methylacrylic acid) triblock copolymer. Nanoscale Res Lett 4(4):341-343

24. Liu R, Tao YH, Zhu Y, Chen MQ, Yang C, Liu XY (2011) Synthesis of double-hydrophilic poly(methylacrylic acid)-poly(ethylene glycol)-poly(methylacrylic acid) triblock copolymers and their micelle formation. Polym Int 60(2):327-332

25. Lowman AM, Peppas NA (2000) Molecular analysis of interpolymer complexation in graft copolymer networks. Polymer 41(1):73-80

26. Gohy JF (2005) Block Copolymer Micelles. Adv Polym Sci 190:65-136

27. Li YB, Li HX, Chen XD, Zhu FM, Yang J, Zhu YB (2010) Complexation of poly(acrylic acid) and poly(ethylene oxide) investigated by enhanced rayleigh scattering method. J Polym Sci, Part B: Polym Phys 48(16):1847-1852

28. Guo M, Yan Y, Zhang H, Yan H, Cao Y, Liu K, Wan S, Huang J, Yue W (2008) Magnetic and pHresponsive nanocarriers with multilayer core-shell architecture for anticancer drug delivery. $\mathrm{J}$ Mater Chem 18:5104-5112

29. Gohy JF, Varshney SK, Jérôme R (2001) Water-soluble complexes formed by poly(2-vinylpyridinium)-block-poly(ethylene oxide) and poly(sodium methacrylate)-block-poly(ethylene oxide) copolymers. Macromolecules 34(10):3361-3366

30. Arimura H, Ohya Y, Ouchi T (2005) Formation of core-shell type biodegradable polymeric micelles from amphiphilic poly(aspartic acid)-block-polylactide diblock copolymer. Biomacromolecules 6(2):720-725

31. Yuan J, Xu Z, Cheng S, Feng L (2002) The aggregation of polystyrene-b-poly(ethyleneoxide)-bpolystyrenetriblockcopolymers in aqueous solution. Eur Polym J 38(8):1537-1546

32. Jiao Z, Wang X, Chen ZM (2010) The advance of amphiphilic block copolymeric micelles as drug delivery. Polym Bull 12:78-83

33. Barzegar-Jalali M, Adibkia K, Valizadeh H, Siahi Shadbad MR, Nokhodchi A, Omidi Y, Mohammadi G, Nezhadi SH, Hasan M (2008) Kinetic analysis of drug release from nanoparticles. J Pharm Pharm Sci 11(1):167-177 
34. Peppas NA (1983) A model of dissolution-controlled solute release from porous drug delivery polymeric systems. J Biomed Mater Res 17(6):1079-1087

35. Ritger PL, Peppas NA (1987) A simple equation for description of solute release I. Fickian and nonfickian release from non-swellable devices in the form of slabs, spheres, cylinders or discs. J Control Release 5(1):23-36

36. Ritger PL, Peppas NA (1987) A simple equation for description of solute release II. Fickian and anomalous release from swellable devices. J Control Release 5(1):37-42

37. Serra L, Doménech J, Peppas NA (2006) Drug transport mechanisms and release kinetics from molecularly designed poly(acrylic acid-g-ethyleneglycol) hydrogels. Biomaterials 27(31):5440-5451 